\title{
Rational use of nonsteroidal anti-inflammatory drugs and proton pump inhibitors in combination for rheumatic diseases
}

\section{Wolfgang W Bolten}

Division of Rheumatology, Klaus-Miehlke Klinik, Wiesbaden, Germany
Correspondence: Wolfgang W Bolten Division of Rheumatology,

Klaus-Miehlke Klinik, Leibnizstrasse 23, 65191 Wiesbaden, Germany

$\mathrm{Tel}+496$ I I 5758I I

Fax +49611575888

Email wbolten@em.uni-frankfurt.de
This article was published in the following Dove Press journal:

Orthopedic Research and Reviews

16 September 2010

Number of times this article has been viewed
Abstract: Nonsteroidal anti-inflammatory drugs (NSAIDs) are successfully used to alleviate pain and inflammation in rheumatic diseases. In an appreciable percentage of cases, the use of systemic NSAIDs is associated with adverse lesions of the gastrointestinal (GI) mucosa up to life-threatening perforations, ulcers, and bleeding. Reliable warning signals mostly do not arise. Therefore, it is important to take preventive measures to reduce the GI risk. One established method is to assign cyclooxygenase 2 (COX-2)-specific inhibitors (coxibs) instead of traditional NSAIDs (tNSAIDs). Coxibs spare in part the endogenous gastroprotective mechanisms. Another reliable choice to improve the GI safety is the comedication of proton pump inhibitors (PPIs) to suppress gastric acid. A fixed NSAID/PPI combination ensures expected protective effects by improving patients' PPI adherence and physicians' PPI prescription persistence. A fixed combination of enteric-coated naproxen and immediate-release esomeprazole has just been approved by the US Food and Drug Administration. PPI combinations with aspirin, other tNSAIDs, and coxibs are desirable. Patients in all risk groups, even patients at low risk of GI adverse events, benefit from concomitant protective measures. Moreover, the literature suggests that NSAID/PPI combinations are cost effective, including for patients in low-GIrisk groups. Pricing of fixed NSAID/PPI combinations will play a pivotal role for their broad acceptance in the future.

Keywords: PPI, NSAID, fixed combination, gastrointestinal, adverse events, prevention

\section{Nonsteroidal anti-inflammatory drugs and upper gastrointestinal tract}

Nonsteroidal anti-inflammatory drugs (NSAIDs), including traditional NSAIDs (tNSAIDs) and cyclooxygenase 2 (COX-2)-selective NSAIDs (coxibs), remain among the most widely prescribed treatments worldwide. They have been successfully used for the alleviation of pain and inflammation in arthritic diseases while conversely causing gastric damage and increased bleeding in some patients. Patients with osteoarthritis (OA) and rheumatoid arthritis (RA) are 2.5-5.5 times more likely to be hospitalized for tNSAID-related gastrointestinal (GI) events than the general population. The absolute risk for serious tNSAID-related GI toxicity remains constant during a treatment period, and the cumulative risk increases over time. ${ }^{1}$ tNSAIDs are associated with a high rate of upper GI symptoms ${ }^{2,3}$ (Figure 1), which are sufficient to cause discontinuation of medication. ${ }^{4}$ Dyspepsia is poorly correlated with endoscopic lesions or GI bleeding. ${ }^{5,6}$ Most patients with serious GI complications have no prior GI symptoms. ${ }^{1}$ There are no reliable warning signals. Ulceration, bleeding, perforation, and strictures are redoubtable adverse outcomes of NSAID treatment. 


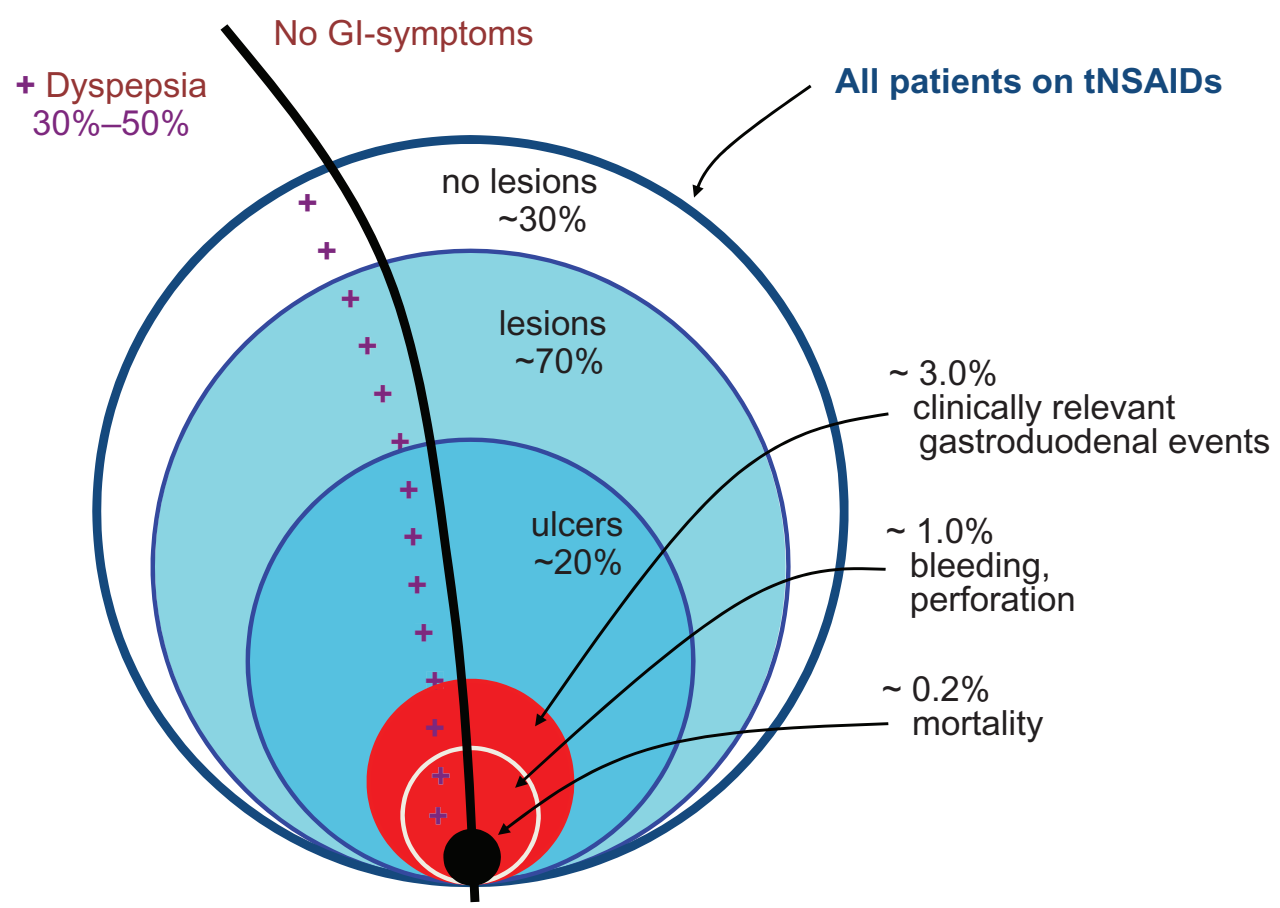

Figure I Spectrum of tNSAID-related gastroduodenal toxicity. GI symptoms like heartburn, dyspepsia, nausea, and/or abdominal pain occur in up to $50 \%$ of tNSAID users. These symptoms are poorly related with endoscopic lesions. Superficial gastroduodenal mucosal lesions (such as erosions) and ulcers may heal spontaneously. Clinically relevant gastroduodenal events are symptomatic ulcers, perforation, and bleeding. A mortality rate of $0.2 \%$ is not negligible. ${ }^{79,80}$

Abbreviations: tNSAID, traditional nonsteroidal anti-inflammatory drug; GI, gastrointestinal.

\section{Risk factors for $\mathbf{G l}$ events}

Obviously, as not all patients taking NSAIDs develop serious complications, risk factors that increase the incidence of GI bleeding, perforation, surgery, and even death exist in some patients. Factors that have been identified as placing patients at increased risk for NSAID-related GI complications include a history of GI event (ulcer, hemorrhage), advanced age ( $>65$ years), higher disability level, high NSAID dosage, and concomitant use of glucocorticoids, anticoagulants, or selective serotonin reuptake inhibitors (SSRIs) ${ }^{1,7,8}$ (Table 1). NSAID therapy without GI protection (placebo), following a successful initial treatment of a NSAID-associated ulcer, was marked by very high rates of recurrent endoscopic ulcers. The relapse rate was $73 \%$ within 6 months. Although the efficacy

Table I GI risk factors with NSAID therapy

\section{Patient inherent risk factors \\ History of $\mathrm{Gl}$ event (ulcer, hemorrhage) \\ Advanced age ( $>65 \mathrm{y})$ \\ Higher disability level \\ Medicine-mediated risks \\ Glucocorticoids \\ Anticoagulants \\ SSRIs}

Abbreviations: Gl, gastrointestinal; NSAID, nonsteroidal anti-inflammatory drug; SSRIs, selective serotonin reuptake inhibitors. of omeprazole $20 \mathrm{mg}$ daily was significantly higher than ranitidine $150 \mathrm{mg}$ twice per day or misoprostol $200 \mu \mathrm{g}$ twice per day, the rate of recurrent endoscopic ulcers was still high at $28 \%$ for omeprazole and $39 \%$ for ranitidine, ${ }^{9}$ as well as $39 \%$ for omeprazole and $52 \%$ for misoprostol, in 6 months. ${ }^{10}$ Patients with a history of bleeding ulcers are considered very high-risk patients. Dyspepsia, sex, smoking, and alcohol consumption were not found to be risk factors among NSAID users. ${ }^{11}$ Life-threatening complications commonly develop even in the absence of dyspeptic symptoms (Figure 1).

\section{tNSAIDs and the stomach}

As a group, tNSAIDs are structurally diverse and differ in pharmacokinetic and pharmacodynamic properties, but ultimately they share the same mode of action. tNSAIDs inhibit COX enzymes to reduce prostaglandin (PG) synthesis. ${ }^{12}$ PGs act locally. They are involved in many processes that cause inflammation, affect constriction and relaxation of blood vessels, and help to clot blood..$^{13}$ Two distinct isoforms of the COX enzyme, with differing sensitivities to NSAIDs, were identified. ${ }^{14} \mathrm{COX}-2$ is selectively upregulated after exposure to proinflammatory cytokines or trauma promoting pain and inflammatory processes. COX-1 is constitutionally present in low abundance in most human tissues, acting as a housekeeping enzyme. tNSAIDs inhibit both COX 
isoenzymes. The inhibition of the same PGs derived from COX-2 in inflamed tissue and from COX-1 in the normal gastric mucosa results in analgesic and anti-inflammatory benefits, at a risk for increased gastric bleeding. ${ }^{15}$

\section{Aspirin and the GI tract}

Since its initial use as an analgesic, aspirin has been proven beneficial for preventing myocardial infarction and stroke in high-risk individuals. Aspirin irreversibly blocks all COX-1 enzymes on blood platelets. Blood platelets do not have a cellular nucleus and are, therefore, unable to newly synthesize COX. Aspirin subsequently inhibits platelet aggregation for the duration of the platelets' life span, making aspirin a potent cardiovascular protective agent. Nonaspirin tNSAIDs do not provide significant long-term inhibition of blood platelet aggregation. They competitively and reversibly inhibit the COX-1 enzyme only during a portion of their dosage interval. Coxibs have no relevant influence on platelet COX-1. ${ }^{16}$ Therefore, cotreatment with aspirin and nonaspirin tNSAID or coxib is unavoidable in some patients. Concurrent use of low-dose aspirin partly or even fully negates the gastroprotective effect of coxibs. ${ }^{17,18}$

Low-dose aspirin at least doubles the risk of major GI bleeding. ${ }^{19}$ A meta-analysis of adverse events of low-dose aspirin in 22 randomized, placebo-controlled trials found a relative risk of 2.07 (95\% confidence interval [CI], 1.61-2.66) for major GI bleeding in patients taking aspirin, with an absolute annual increase of $0.12 \% .{ }^{19}$ The rate of recurrent ulcer complications during follow-up of 12 months in patients who continued aspirin therapy was $1.6 \%$ with lansoprazole and $14.8 \%$ with placebo (hazard ratio $[\mathrm{HR}]=9.6 ; 95 \% \mathrm{CI}$, $1.2-76.1) .{ }^{20}$ The rate of recurrent ulcer bleeding was $0.7 \%$ with aspirin $80 \mathrm{mg}$ plus esomeprazole and $8.6 \%$ with clopidogrel $(P=0.008) .{ }^{21}$ Among low-dose aspirin recipients who had peptic ulcer bleeding, continued aspirin therapy together with a proton pump inhibitor (PPI) may increase the risk for recurrent bleeding but potentially reduces mortality rates. $^{22}$ Rates of recurrent ulcer bleeding in Helicobacter pylori-infected aspirin users with ulcer bleeding in a 6-month randomized trial of $H$ pylori eradication vs maintenance therapy with omeprazole were comparable (1.9\% vs $0.9 \%$, not significant ). ${ }^{20}$ Among users of other NSAIDs, omeprazole was superior to the eradication of $H$ pylori in preventing recurrent ulcer bleeding $(4.4 \%$ vs $18.8 \%, P=0.005) .{ }^{23}$ Prophylaxis with a PPI effectively prevents recurrent upper GI bleeding with low-dose aspirin, despite failure of $H$ pylori eradication and concomitant use of tNSAIDs. ${ }^{20}$ In a case-control study of low-dose aspirin users with upper GI bleeding, H pylori infection was identified as an independent risk factor of upper GI bleeding (odds ratio [OR] $=4.7$ ). ${ }^{24}$ After endoscopic ulcer bleeding associated with low-dose aspirin, patients received either low-dose aspirin $80 \mathrm{mg} / \mathrm{d}$ again or placebo for 8 weeks. Both groups subsequently received a daily dose of an oral PPI. During follow-up, the incidence of recurrent ulcer bleeding at 30 days was $10.3 \%$ in the low-dose aspirin group and 5.4\% in the placebo group $(\mathrm{HR}=1.9)$. However, patients who received low-dose aspirin in combination with PPI had a lower mortality rate within 8 weeks attributable to cardiovascular, cerebrovascular, or GI complications (1.3\% vs $10.3 \%)$. Significantly more patients in the placebo group died during follow-up. ${ }^{22}$ Patients without cardiovascular risk factors, who receive antithrombotic therapy (primary prophylaxis), should discontinue low-dose aspirin therapy, unless the vascular risk profile worsens. Patients with upper GI bleeding, who require secondary cardiovascular prophylaxis, should resume low-dose aspirin therapy as soon as the cardiovascular risks outweigh the GI risks (usually within 7 days). ${ }^{25}$ After low-dose aspirin withdrawal, the delay to thrombotic events is short (generally reported to be 7-30 days), and events often occur after 7-10 days. ${ }^{25}$ The combination of low-dose aspirin and PPIs results in less recurrent GI bleeding than a switch to clopidogrel alone during the following 12 months. ${ }^{21,26}$ Aspirin is being assessed for the reduction of cancer risk at several sites, including the colorectum, stomach, esophagus, breast, ovary, and lung. The benefits of low-dose aspirin therapy must be weighed against its attendant risk in patients who develop peptic ulcer bleeding. In general, it must be ensured that aspirin-treated patients, and most certainly those who are at GI risk, adhere to a PPI comedication.

\section{Coxibs and gastroduodenum}

Drugs selectively inhibiting COX-2 relieve joint pain and inflammation with less GI toxicity than nonselective NSAIDs. Coxibs decrease the risk for both endoscopic NSAID ulcers and serious NSAID ulcer complications when compared with nonselective NSAIDs. ${ }^{17,27-29}$ Although coxibs reduce ulcers and their complications, these adverse events are not completely eliminated, and the residual event rate is high in at-risk patients, ${ }^{29-32}$ partly as a result of channeling high-risk patients into coxib use.

Concerns have been raised about the cardiovascular safety of both coxibs and tNSAIDs. ${ }^{33}$ The recent events around the increased cardiovascular risk associated with rofecoxib compared with naproxen ${ }^{29,34}$ have led to scrutiny of all coxibs. ${ }^{35}$ Coxibs are currently prescribed substantially less often than tNSAIDs. In 
2007, the coxibs, such as celecoxib and etoricoxib, accounted for approximately $5.8 \%$ of total NSAID prescriptions in the United Kingdom and approximately $20 \%$ of the total spent, ${ }^{36}$ despite the fact that an increased risk of serious adverse cardiovascular events may be a class effect for all NSAIDs except aspirin.

The previous guidance from the British National Institute for Health and Clinical Excellence recommended that coxibs should not be used routinely and used only in patients at high risk of developing serious GI adverse events on tNSAIDs. In addition, the guidance stated that there was no evidence to justify the simultaneous prescription of gastroprotective agents and coxibs. ${ }^{37,38}$

As part of the development of the latest British National Institute for Health and Clinical Excellence (NIH) guideline, an economic reevaluation of coxibs, tNSAIDs, and the addition of gastroprotective agents to these treatments was performed. It was based on the largest randomized controlled trials, such as the Celecoxib Long-term Arthritis Safety Study (CLASS), ${ }^{28}$ the Therapeutic Arthritis Research and Gastrointestinal Event Trial (TARGET), ${ }^{17,39}$ and the Multinational Etoricoxib and Diclofenac Arthritis Long-term Study (MEDAL), ${ }^{40}$ reporting GI and cardiovascular events with currently licensed NSAIDs. The primary outcome measure for the economic analysis was quality-adjusted life years. The analysis from the United Kingdom shows that prescribing a PPI for OA patients who are taking a tNSAID or coxib is cost effective, if the cheapest PPI is used. ${ }^{36}$ Adding a PPI to a coxib (used at the lowest licensed dose) is a cost-effective option, even for patients at low risk of GI adverse events. ${ }^{36}$

\section{Misoprostol and GI safety}

The synthetic oral PG misoprostol $800 \mu \mathrm{g} / \mathrm{d}$ significantly reduced the risk of NSAID ulcer complications, such as perforation, bleeding, or obstruction. ${ }^{28,41}$ Misoprostol caused diarrhea at all doses, although significantly more at $800 \mu \mathrm{g} / \mathrm{d}$ than at $400 \mu \mathrm{g} / \mathrm{d}$. As a result of the adverse events, this medication is rarely prescribed. There is a fixed combination of misoprostol and diclofenac available on the market.

\section{Lower GI tract, NSAIDs, and PPI}

NSAID-related injury to both the small and the large bowel includes occult and frank bleeding, perforation, obstruction, acute colitis, and exacerbation of existing colon disease. Small intestinal micro bleeding, protein loss, and malabsorption have been attributed to an NSAID-related enteropathy. ${ }^{42}$ Intestinal permeability is markedly increased shortly after treatment with NSAIDs. ${ }^{43,44}$ Increase of small intestinal inflammation occurs later. ${ }^{45}$
In a post hoc analysis of the Vioxx Gastrointestinal Outcomes Research (VIGOR) trial, ${ }^{29}$ the occurrence of serious lower GI clinical events was examined. Serious lower GI events occurred at a rate of $0.9 \%$ per year in RA patients taking the tNSAID naproxen and accounted for nearly $40 \%$ of the serious GI events developed among these patients. In comparison, the incidence rate of serious lower GI events was 54\% lower among patients using a coxib. ${ }^{46}$ A clinically meaningful decrease in hemoglobin was seen in significantly more patients taking ibuprofen $(5.4 \%)$ than in those taking placebo or aspirin plus rofecoxib $(0.8 \%-1.6 \%){ }^{18}$

In capsule endoscopic studies, the coxib led to a significant reduction in lower bowel lesions compared with the combination of naproxen ${ }^{47}$ or ibuprofen with a PPI each. ${ }^{48}$ PPIs could not hinder the development of tNSAID-induced lesions in the lower GI tract. Small-bowel damage caused by NSAIDs is unrelated to age, sex, or duration of NSAID ingestion beyond 3 months of therapy. ${ }^{29,46,49}$ Capsule endoscopy demonstrates evidence of macroscopic injury to the small intestine, in up to $68 \%$ of volunteers resulting from 2 weeks of ingestion of slow-release diclofenac. ${ }^{50}$ Coxibs cause minimal or no damage to the small bowel when taken for a short time. ${ }^{47}$ Long-term use ( $>3$ months) of tNSAIDs and coxibs causes comparable small bowel damage $(50 \%-68 \%){ }^{50}$

In the Study of Celecoxib or Diclofenac and Omeprazole for Gastrointestinal (GI) Safety in High GI Risk Patients with Arthritis (CONDOR), the rate of clinically significant GI events was 4 times higher in patients receiving slow-release diclofenac $75 \mathrm{mg}$ twice a day plus omeprazole $20 \mathrm{mg}(3.8 \%)$ than in patients receiving celecoxib $200 \mathrm{mg}$ twice a day $(0.9 \% ; P<0.0001) .{ }^{51}$ The main driving force behind the primary end point was a hemoglobin decrease of $20 \mathrm{~g} / \mathrm{L}$ or more. Ten of 2,238 patients in the celecoxib group but 53 of 2,246 patients in the diclofenac plus omeprazole group had clinically significant anemia of presumed occult GI origin, including possible blood loss from the small bowel. Attrition due to GI adverse events was significantly $(P=0.0006)$ less prevalent among patients taking celecoxib $(6 \%)$ than among patients taking diclofenac plus omeprazole $(8 \%) .^{51}$

\section{Proton pump inhibitors Introduction}

PPIs are one of the most frequently prescribed classes of drugs in the world because they combine a high level of efficacy with low toxicity. The suppression of gastric acid via inhibition of the proton pumps is a successfully used method to prevent GI lesions caused by NSAIDs. On the other hand, studies consistently show that PPIs are being 
overprescribed worldwide in both primary and secondary care. Between $25 \%$ and $70 \%$ of patients taking these drugs have no appropriate indication. ${ }^{52}$

\section{Side effects}

PPIs as a class are remarkably safe and effective for persons with peptic ulcer disorders. Serious adverse events are extremely rare for PPIs, with case reports of interstitial nephritis with omeprazole, hepatitis with omeprazole and lansoprazole, and disputed visual disturbances with pantoprazole and omeprazole. ${ }^{53}$

An increase in the prevalence of pneumonia and Campylobacter enteritis is reported, as well as a doubling of the risk of infection with Clostridium difficile. ${ }^{54}$ PPIs may not only interfere with calcium absorption by induction of hypochlorhydria but also reduce bone resorption by inhibition of osteoclastic vacuolar proton pumps. ${ }^{55}$ Acute interstitial nephritis and osteoporosis are unusual but consequences of treatment with PPIs are recognized. ${ }^{55}$ PPIs possibly increase the risk of fractures. Based on review of several epidemiological studies, the US Food and Drug Administration (FDA) reported that those who received high doses of PPIs or used them for 1 year or more were at greatest risk of fractures of the hip, wrist, and spine.$^{56}$ Individuals at risk for osteoporosis should combine adequate vitamin $\mathrm{D}$ and calcium supplementation. Such side effects are rare and responsive to medical care. But $25 \%-70 \%$ of prescriptions around the world are without appropriate indication. ${ }^{52}$ Treatment without indication, as well as indicated but not realized treatment, may be the more remarkable problem.

\section{Gl prevention}

The presence of acid in the stomach alone does not cause an ulcer development. ${ }^{57}$ Mucosal PG deficiency leads to a decrease in the body's protective measures, allowing the acid to destroy the tissue. Without acid, an ulcer unlikely occurs. Optional and/or in addition to the usage of COX-1 sparing drugs instead of tNSAIDs the approach to ulcer prevention and upper GI symptom management in NSAID users is the suppression of the production of gastric acid. Therefore, a rationale exists for combining NSAID treatment with acid suppression therapy. Antacids and histamine $\mathrm{H}_{2}$-receptor antagonists $\left(\mathrm{H}_{2} \mathrm{RAs}\right)$ administered in ulcer treatment do not prevent tNSAID-induced gastric ulcers, ${ }^{1}$ but PPIs do. ${ }^{36,58}$

Elevation of the intragastric $\mathrm{pH}$ reduces the risk of gastroduodenal ulcers. PPIs are significantly more effective than $\mathrm{H}_{2} \mathrm{RAs}$ in achieving and sustaining an intragastric $\mathrm{pH}$ above 4.0. ${ }^{59}$ Concomitant PPIs have been shown to prevent endoscopic ulcer recurrence among long-term NSAID users. $^{41,60,61}$ In a controlled 12-week study, NSAID users developed recurrence of endoscopic gastric ulcer in $49 \%$ of the placebo group, $20 \%$ on lansoprazole $15 \mathrm{mg}, 18 \%$ on lansoprazole $30 \mathrm{mg}$, and 7\% on misoprostol. ${ }^{61}$

In RA patients with one or more risk factors, incidence of endoscopic ulcers after 6 months was $10 \%$ on pantoprazole $20 \mathrm{mg}$, $7 \%$ on pantoprazole $40 \mathrm{mg}$, and $11 \%$ on omeprazole $20 \mathrm{mg} .{ }^{62}$ There have not been any studies demonstrating the efficacy of PPIs in the primary prevention of serious NSAID ulcer complications.

PPIs have been shown to provide a greater level of acid suppression than $\mathrm{H}_{2}$ RAs. ${ }^{59}$ In outcome trials, PPIs have been shown to prevent ulcer recurrence associated with NSAID use. ${ }^{9,10,63,64}$ In the Omeprazole versus Misoprostol for NSAID-induced Ulcer Management (OMNIUM) trial, the proportion of patients, who remained in remission at 6 months, was significantly higher on omeprazole $(61 \%)$ than on misoprostol (48\%) or placebo $(27 \%) .{ }^{10}$ From Verification of Esomeprazole for NSAID Ulcers and Symptoms (VENUS) and Prevention of Latent Ulceration Treatment Options (PLUTO) at 6 months, the estimated percentages of patients developing endoscopic ulcers were $20 \%$ and $12 \%$ on placebo, $5 \%$ and $5 \%$ on esomeprazole $20 \mathrm{mg}$, and $5 \%$ and $4 \%$ on esomeprazole $40 \mathrm{mg} .{ }^{65}$ In contrast, standard doses of $\mathrm{H}_{2} \mathrm{RAs}$ are not effective for the prevention of gastric NSAID ulcers. High doses of $\mathrm{H}_{2} \mathrm{RAs}$, however, may prevent both gastric and duodenal endoscopic NSAID ulcers. ${ }^{66,67}$

In interventional studies among high-risk patients with a recent history of ulcer bleeding, treatment with celecoxib was as effective as treatment with diclofenac plus omeprazole for the prevention of recurrent bleeding, but neither strategy completely eliminated the risk. ${ }^{30} 19 \%$ of patients receiving celecoxib and $26 \%$ of patients receiving diclofenac plus omeprazole had recurrent ulcers. With a combined end point of bleeding and endoscopic ulcers, 24\% of patients receiving celecoxib and $32 \%$ of patients receiving diclofenac plus omeprazole had recurrent ulcers. ${ }^{30,68}$ Recurrent ulcer complications at 24 weeks occurred in $3.7 \%$ of patients receiving celecoxib and $6.3 \%$ of patients receiving naproxen plus lansoprazole. ${ }^{69}$ Recurrent NSAID ulcer complications in NSAID users at very high risk were successfully prevented by a combination therapy of celecoxib and esomeprazole $(0 \%)$ and reduced to $9 \%$ by a celecoxib monotherapy. ${ }^{70}$ Patients at very high risk for recurrent ulcer bleeding, who need continued NSAID treatment, might benefit from combination treatment with a coxib in combination with a PPI (Table 2). 
Table $2 \mathrm{Gl}$ risk management in NSAID-treated patients

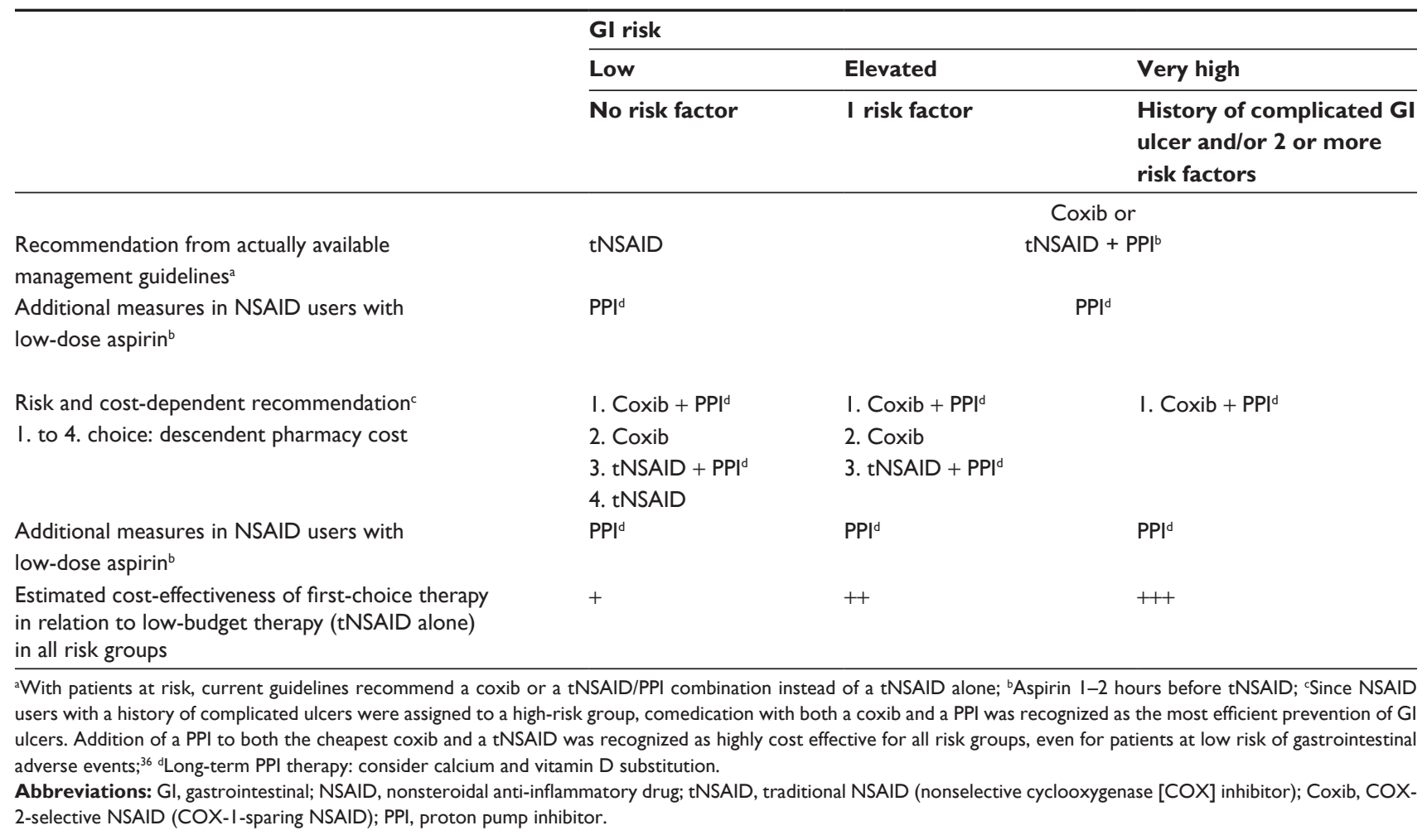

\section{Compliance and cost}

Therapeutic noncompliance is a major issue in health care, having important negative consequences for clinical outcome and for health care costs. It is evident that noncompliance always results in a reduction in efficacy or loss of expected protective effects. Poor compliance with PPI treatment is not uncommon and well known among patients with gastroesophageal reflux disease (GERD). Several studies have shown that $25 \%{ }^{71}-45 \%{ }^{72}$ of patients take less than $80 \%$ of their prescribed PPIs during treatment. In a retrospective cohort study of GERD patients, comparing compliant with noncompliant PPI users, a sizeable fraction (32\%) of GERD patients intended for PPI medication were noncompliant. ${ }^{73}$ In a study conducted in a national sample of managed care plans, low PPI adherence and prescription persistence accounted for Barrett esophagus or GERD in patients without Barrett esophagus one-third of the time during the year. ${ }^{74}$ Patients are using intermittent or on-demand therapy for symptomatic complaints.

Less than half of the patients taking tNSAIDs suffer from dyspepsia. Voluntary cooperation of these nondyspeptic patients in taking PPI as prescribed persistently might be disappointing, whereas adherence with PPI therapy in these patients is crucial for an appropriate individual risk reduction. Studies of different diseases and therapies have shown that higher compliance rates can lead to beneficial outcomes with respect to health and cost. GERD patients who were compliant with PPI therapy experienced a significantly bigger reduction in the number of visits and a 3 -fold reduction in the number of hospitalization days per year. The inpatient utilization reduction decreased the overall medical cost, although the pharmacy costs increased, as expected. Total annual per capita costs for compliant patients declined by US $\$ 3,261$ when compared with the pre-PPI period. In contrast, the cost reduction among noncompliant patients amounted to only US $\$ 2,406$ per patient per year $(P=0.012) .{ }^{73}$ The cost effect of therapeutic noncompliance among different drug-disease combinations varies substantially. ${ }^{75,76}$

Taking costs into consideration, case can be made for coprescribing PPI for all patients receiving a tNSAID since PPIs are inexpensive and likely to be associated with cost saving. ${ }^{77}$ Addition of a PPI to both coxibs and tNSAIDs in patients from CLASS, ${ }^{28}$ TARGET, ${ }^{17,39}$ and MEDAL study ${ }^{40}$ was highly cost effective in all patient groups, even in patients at low risk for GI adverse events, if the cheapest PPI was used. ${ }^{36}$ Adding a PPI to a coxib (used at the lowest licensed dose) was a cost-effective option, even for patients at low risk of GI adverse events. ${ }^{36}$ Low compliance restricts this favorable result. With fixed NSAID/PPI combinations, 
this problem is diminished. The degree of the postulated advantage is determined by the price.

\section{Rational use of fixed NSAID/PPI combination}

PLUTO and VENUS showed the rate of ulcer development was reduced by PPI in patients taking either coxibs or tNSAIDs. ${ }^{65}$ New data indicate that coprescribing gastroprotective agents like PPI with both coxibs and tNSAIDs is beneficial. ${ }^{36,65,70,77}$ Before those data were available, management guidelines recommended the use of GI supportive therapy only in patients at risk for ulceration rather than in all NSAID users. Based on the outcome of the largest randomized controlled trials, such as the CLASS, ${ }^{28}$ TARGET, ${ }^{17,39}$ and the MEDAL study ${ }^{40}$ reporting GI and cardiovascular events with currently licensed NSAIDs, members of the British National Institute for Health and Clinical Excellence Osteoarthritis Guideline Development Group now recommend prescription of tNSAIDs or coxibs in combination with a PPI, assuming that this is cost effective. They argue that the number of adverse events avoided is a very good value for money. However, there is no clear evidence whether there are significant cost differences among tNSAIDs and among coxibs. ${ }^{36}$ An additional advantage of PPI comedication is the lower incidence of heartburn, acid regurgitation, and sleep disturbance compared with placebo. ${ }^{65}$ Future guidelines will probably recommend comedication of tNSAIDs, as well as coxibs with a PPI, as first-line medication for all risk groups (Table 1).

Fixed NSAID/PPI combinations will likely help to solve the above-discussed compliance problem. The first representative of this group of drugs for treating the signs and symptoms of OA, RA, and ankylosing spondylitis, and for decreasing the risk of developing gastric ulcers in patients at risk has just been approved by the FDA (www.fda.gov). This approval was based on data from 2 pivotal studies (http:// www.pozen.com/product/poster.asp). In both studies, the primary end point was the cumulative incidence of gastric ulcers throughout a period of 6 months. The incidence was $4.1 \%$ for the naproxen/esomeprazole fixed-combination group and $23.1 \%$ among patients given enteric-coated naproxen. The incidences of gastric ulcer in the second trial were $7.1 \%$ and $24.3 \%$, respectively. Regulatory submission of this delayedrelease combination of enteric-coated naproxen (375 or $500 \mathrm{mg}$ ) and immediate-release esomeprazole $(20 \mathrm{mg})$ was filed to the European authorities in October 2009.

Aspirin has emerged as the most likely NSAID for use in chemoprevention because of its known cardiovascular benefit.
Furthermore, evidence clearly shows a chemopreventive effect of aspirin and other NSAIDs on colorectal cancer and probably other cancer types. ${ }^{78}$ Therefore, the development of additional fixed combinations of a PPI with other tNSAIDs, as well as a fixed-dose formulation with low-dose aspirin or with a coxib, is desirable to make NSAID treatment safer. The price of the fixed-combination medicine will determine the frequency of prescription.

\section{Summary}

NSAIDs have been successfully used for the alleviation of pain and inflammation. However, NSAIDs can cause gastric damage and bleeding at any time during the treatment period. As NSAID dyspepsia is not correlated with NSAID-associated mucosal damage, dyspepsia does not reflect the mucosal situation and is not considered to be a red flag for ulcer development. The possibility of asymptomatic development of serious GI toxicity makes it necessary to observe risk factors that enhance the incidence of GI toxicity. Risk factors make it easier to identify the patient who needs preventive measures (Table 2). History of GI event, age $>65$ years, higher disability level, and concomitant use of glucocorticoids or anticoagulants or SSRIs highlight the patient at risk. The history of a bleeding ulcer indicates patients at highest risk. Measures to decrease GI risk are based on several mechanisms.

NSAIDs inhibit COX enzymes to reduce PG synthesis. There are 2 distinct isoforms of the COX enzyme. The COX-1 acts as a housekeeping enzyme, and the selectively upregulating COX-2 mediates inflammation. The tNSAID-induced concomitant inhibition of PGs, due to induced COX-2 in inflammatory tissue and COX-1 in the normal gastric mucosa, not only causes analgesic and anti-inflammatory benefits but also increases the risk for gastric deterioration. COX2-selective inhibition spares the COX-1 and preserves the gastroprotective mechanisms.

Mucosal PG deficiency alone may not cause the development of an ulcer. Without the presence of acid, there may be no ulcer in the stomach. Acid from the stomach attacks the vulnerable PG-deficient mucous layer and initiates mucosal destruction. PPI cotherapy reduces acid production and consequently diminishes GI risk irrespective of the NSAID chosen. New data from the United Kingdom indicates that cotreatment with a PPI is cost effective, without dependence on the patient's individual risk profile and without dependence on the selectivity of the COX inhibitor. However, poor compliance with PPI treatment has negative consequences for clinical outcome and for health care costs. 
Fixed NSAID/PPI combinations may improve compliance. A fixed tNSAID/PPI preparation was just approved by the FDA. One can hope that other fixed tNSAID/PPI combinations, as well as aspirin/PPI and coxib/PPI, will follow. In the future, NSAIDs might be replaced by fixed NSAID/PPI combinations.

The way toward safer NSAID therapy with the help of concurrent prescriptions of GI drugs is influenced by many factors, such as the costs of comedication, prescriber and patients' compliance, controversial efficacy, and the influence of these drugs on the patients' quality of life. With fixed NSAID/PPI combinations, some of these difficulties are eliminated. Nevertheless, the determining factor for broad acceptance will be the price of the drug.

\section{Disclosure}

The authors report no conflicts of interest in this work.

\section{References}

1. Singh G. Recent considerations in nonsteroidal anti-inflammatory drug gastropathy. Am J Med. 1998;105(1B):S31-S38.

2. Smith JB, Willis AL. Aspirin selectively inhibits prostaglandin production in human platelets. Nat New Biol. 1971;231(25):235-237.

3. Collier JG, Flower RJ. Effect of aspirin on human seminal prostaglandins. Lancet. 1971;2(7729):852-853.

4. Singh G, Rosen RD. NSAID induced gastrointestinal complications: the ARAMIS perspective - 1997. Arthritis, Rheumatism, and Aging Medical Information System. J Rheumatol Suppl. 1998;51:8-16.

5. Brooks PM, Day RO. Nonsteroidal antiinflammatory drugs - differences and similarities. N Engl J Med. 1991;324(24):1716-1725.

6. Larkai EN, Smith JL, Lidsky MD, Graham DY. Gastroduodenal mucosa and dyspeptic symptoms in arthritic patients during chronic nonsteroidal anti-inflammatory drug use. Am J Gastroenterol. 1987;82(11):1153-1158.

7. Lanza FL. A guideline for the treatment and prevention of NSAIDinduced ulcers. Members of the ad hoc committee on practice parameters of the American College of Gastroenterology. Am J Gastroenterol. 1998;93(11):2037-2046.

8. Loke YK, Trivedi AN, Singh S. Meta-analysis: gastrointestinal bleeding due to interaction between selective serotonin uptake inhibitors and non-steroidal anti-inflammatory drugs. Aliment Pharmacol Ther. 2008; 27(1):31-40.

9. Yeomans ND, Tulassay Z, Juhasz L, et al. A comparison of omeprazole with ranitidine for ulcers associated with nonsteroidal antiinflammatory drugs. Acid Suppression Trial: Ranitidine versus Omeprazole for NSAID-associated Ulcer Treatment (ASTRONAUT) Study Group. N Engl J Med. 1998;338(11):719-726.

10. Hawkey CJ, Karrasch JA, Szczepanski L, et al. Omeprazole compared with misoprostol for ulcers associated with nonsteroidal antiinflammatory drugs. Omeprazole versus Misoprostol for NSAID-induced Ulcer Management (OMNIUM) Study Group. N Engl J Med. 1998;338(11): $727-734$.

11. Gabriel SE, Jaakkimainen L, Bombardier C. Risk for serious gastrointestinal complications related to use of nonsteroidal anti-inflammatory drugs. A meta-analysis. Ann Intern Med. 1991;115(10):787-796.

12. Vane JR. Inhibition of prostaglandin synthesis as a mechanism of action for aspirin-like drugs. Nat New Biol. 1971;231(25):232-235.

13. Bergstrom S, Samuelsson B. Isolation of prostaglandin E1 from human seminal plasma. Prostaglandins and related factors 11. J Biol Chem. 1962;237:3005-3006.
14. Fu JY, Masferrer JL, Seibert K, Raz A, Needleman P. The induction and suppression of prostaglandin $\mathrm{H}_{2}$ synthase (cyclooxygenase) in human monocytes. J Biol Chem. 1990;265(28):16737-16740.

15. Flower R, Gryglewski R, Herbaczynska-Cedro K, Vane JR. Effects of anti-inflammatory drugs on prostaglandin biosynthesis. Nat New Biol. 1972;238(82):104-106.

16. Catella-Lawson F, Reilly MP, Kapoor SC, et al. Cyclooxygenase inhibitors and the antiplatelet effects of aspirin. N Engl J Med. 2001;345(25): 1809-1817.

17. Schnitzer TJ, Burmester GR, Mysler E, et al. Comparison of lumiracoxib with naproxen and ibuprofen in the Therapeutic Arthritis Research and Gastrointestinal Event Trial (TARGET), reduction in ulcer complications: randomised controlled trial. Lancet. 2004; 364(9435):665-674.

18. Laine L, Maller ES, Yu C, Quan H, Simon T. Ulcer formation with lowdose enteric-coated aspirin and the effect of COX-2 selective inhibition: a double-blind trial. Gastroenterology. 2004;127(2):395-402.

19. McQuaid KR, Laine L. Systematic review and meta-analysis of adverse events of low-dose aspirin and clopidogrel in randomized controlled trials. Am J Med. 2006;119(8):624-638.

20. Lai KC, Lam SK, Chu KM, et al. Lansoprazole for the prevention of recurrences of ulcer complications from long-term low-dose aspirin use. N Engl J Med. 2002;346(26):2033-2038.

21. Chan FK, Ching JY, Hung LC, et al. Clopidogrel versus aspirin and esomeprazole to prevent recurrent ulcer bleeding. $N$ Engl J Med. 2005;352(3):238-244.

22. Sung JJ, Lau JY, Ching JY, et al. Continuation of low-dose aspirin therapy in peptic ulcer bleeding: a randomized trial. Ann Intern Med. 2010;152(1):1-9.

23. Chan FK, Chung SC, Suen BY, et al. Preventing recurrent upper gastrointestinal bleeding in patients with Helicobacter pylori infection who are taking low-dose aspirin or naproxen. $N$ Engl $J$ Med. 2001;344(13):967-973.

24. Lanas A, Fuentes J, Benito R, Serrano P, Bajador E, Sainz R. Helicobacter pylori increases the risk of upper gastrointestinal bleeding in patients taking low-dose aspirin. Aliment Pharmacol Ther. 2002; 16(4):779-786.

25. Barkun AN, Bardou M. Aspirin withdrawal in acute peptic ulcer bleeding: are we harming patients? Ann Intern Med. 2010;152(1):52-53, $\mathrm{W}-12$.

26. Lai KC, Chu KM, Hui WM, et al. Esomeprazole with aspirin versus clopidogrel for prevention of recurrent gastrointestinal ulcer complications. Clin Gastroenterol Hepatol. 2006;4(7):860-865.

27. Langman MJ, Jensen DM, Watson DJ, et al. Adverse upper gastrointestinal effects of rofecoxib compared with NSAIDs. JAMA. 1999;282(20):1929-1933.

28. Silverstein FE, Faich G, Goldstein JL, et al. Gastrointestinal toxicity with celecoxib vs nonsteroidal anti-inflammatory drugs for osteoarthritis and rheumatoid arthritis: the CLASS study: A randomized controlled trial. Celecoxib Long-term Arthritis Safety Study. JAMA. 2000;284(10):1247-1255.

29. Bombardier C, Laine L, Reicin A, et al; VIGOR Study Group. Comparison of upper gastrointestinal toxicity of rofecoxib and naproxen in patients with rheumatoid arthritis. N Engl J Med. 2000;343(21): $1520-1528$.

30. Chan FK, Hung LC, Suen BY, et al. Celecoxib versus diclofenac and omeprazole in reducing the risk of recurrent ulcer bleeding in patients with arthritis. N Engl J Med. 2002;347(26):2104-2110.

31. Laine L, Bombardier C, Hawkey CJ, et al. Stratifying the risk of NSAIDrelated upper gastrointestinal clinical events: results of a double-blind outcomes study in patients with rheumatoid arthritis. Gastroenterology. 2002;123(4):1006-1012.

32. Hawkey CJ, Langman MJ. Non-steroidal anti-inflammatory drugs: overall risks and management. Complementary roles for COX-2 inhibitors and proton pump inhibitors. Gut. 2003;52(4):600-608.

33. Bolten WW. Problem of the atherothrombotic potential of non-steroidal anti-inflammatory drugs. Ann Rheum Dis. 2006;65(1):7-13. 
34. Bresalier RS, Sandler RS, Quan H, et al. Cardiovascular events associated with rofecoxib in a Colorectal Adenoma Chemoprevention Trial. N Engl J Med. 2005;352(11):1092-1102.

35. Kim PS, Reicin AS. Rofecoxib, Merck, and the FDA. $N$ Engl $J$ Med. 2004;351(27):2875-2878; author reply 2875-2878.

36. Latimer N, Lord J, Grant RL, O'Mahony R, Dickson J, Conaghan PG. Cost effectiveness of COX 2 selective inhibitors and traditional NSAIDs alone or in combination with a proton pump inhibitor for people with osteoarthritis. BMJ. 2009;339:b2538.

37. Conaghan PG, Dickson J, Grant RL. Care and management of osteoarthritis in adults: summary of NICE guidance. BMJ. 2008;336(7642): 502-503.

38. National Institute for Health and Clinical Excellence. Osteoarthritis: national clinical guideline for care and management in adults 2008 http://www.nice.org.uk/nicemedia/live/11926/39720/39720.pdf.

39. Farkouh ME, Kirshner H, Harrington RA, et al. Comparison of lumiracoxib with naproxen and ibuprofen in the Therapeutic Arthritis Research and Gastrointestinal Event Trial (TARGET), cardiovascular outcomes randomised controlled trial. Lancet. 2004;364(9435):675-684.

40. Laine L, Curtis SP, Cryer B, Kaur A, Cannon CP. Assessment of upper gastrointestinal safety of etoricoxib and diclofenac in patients with osteoarthritis and rheumatoid arthritis in the Multinational Etoricoxib and Diclofenac Arthritis Long-term (MEDAL) programme: a randomised comparison. Lancet. 2007;369(9560):465-473.

41. Rostom A, Dube C, Wells G, et al. Prevention of NSAID-induced gastroduodenal ulcers. Cochrane Database Syst Rev. 2002;(4):CD002296.

42. Bjarnason I, Hayllar J, MacPherson AJ, Russell AS. Side effects of nonsteroidal anti-inflammatory drugs on the small and large intestine in humans. Gastroenterology. 1993;104(6):1832-1847.

43. Bjarnason I, Williams P, Smethurst P, Peters TJ, Levi AJ. Effect of non-steroidal anti-inflammatory drugs and prostaglandins on the permeability of the human small intestine. Gut. 1986;27(11):1292-1297.

44. Jenkins RT, Rooney PJ, Jones DB, Bienenstock J, Goodacre RL. Increased intestinal permeability in patients with rheumatoid arthritis: a side-effect of oral nonsteroidal anti-inflammatory drug therapy? $\mathrm{Br}$ J Rheumatol. 1987;26(2):103-107.

45. Bjarnason I, Williams P, So A, et al. Intestinal permeability and inflammation in rheumatoid arthritis: effects of non-steroidal antiinflammatory drugs. Lancet. 1984;2(8413):1171-1174.

46. Laine L, Connors LG, Reicin A, et al. Serious lower gastrointestinal clinical events with nonselective NSAID or coxib use. Gastroenterology. 2003;124(2):288-292.

47. Goldstein JL, Eisen GM, Lewis B, Gralnek IM, Zlotnick S, Fort JG. Video capsule endoscopy to prospectively assess small bowel injury with celecoxib, naproxen plus omeprazole, and placebo. Clin Gastroenterol Hepatol. 2005;3(2):133-141.

48. Goldstein JL, Eisen GM, Lewis B, et al. Small bowel mucosal injury is reduced in healthy subjects treated with celecoxib compared with ibuprofen plus omeprazole, as assessed by video capsule endoscopy. Aliment Pharmacol Ther. 2007;25(10):1211-1222.

49. Silverstein FE, Graham DY, Senior JR, et al. Misoprostol reduces serious gastrointestinal complications in patients with rheumatoid arthritis receiving nonsteroidal anti-inflammatory drugs. A randomized, double-blind, placebo-controlled trial. Ann Intern Med. 1995;123(4):241-249.

50. Maiden L. Capsule endoscopic diagnosis of nonsteroidal antiinflammatory drug-induced enteropathy. J Gastroenterol. 2009;44 (Suppl 19): S64-S71.

51. Chan FKL, Lanas A, Scheiman J, Berger MF, Nguyen H, Goldstein JL. Celecoxib versus omeprazole and diclofenac in patients with osteoarthritis and rheumatoid arthritis (CONDOR): a randomised trial. The Lancet. In press 2010.

52. Forgacs I, Loganayagam A. Overprescribing proton pump inhibitors. BMJ. 2008;336(7634):2-3.

53. Thomson AB, Sauve MD, Kassam N, Kamitakahara H. Safety of the long-term use of proton pump inhibitors. World J Gastroenterol. 2010;16(19):2323-2330.
54. Dial S, Delaney JA, Barkun AN, Suissa S. Use of gastric acid-suppressive agents and the risk of community-acquired Clostridium difficile-associated disease. JAMA. 2005;294(23):2989-2995.

55. Yang YX, Lewis JD, Epstein S, Metz DC. Long-term proton pump inhibitor therapy and risk of hip fracture. JAMA. 2006;296(24): 2947-2953.

56. Communication FDS. Possible increased risk of fractures of the hip, wrist, and spine with the use of proton pump inhibitors. Postmarket Drug Safety Information for Patients and Providers. 2010. http://www.fda. gov/Drugs/DrugSafety/PostmarketDrugSafetyInformationforPatientsandProviders/ucm 213206.htm

57. Gustafson J, Welling D. "No acid, no ulcer" - 100 years later: a review of the history of peptic ulcer disease. J Am Coll Surg. 2010;210(1):110-116.

58. Vonkeman HE, Fernandes RW, van der Palen J, van Roon EN, van de Laar MA. Proton-pump inhibitors are associated with a reduced risk for bleeding and perforated gastroduodenal ulcers attributable to nonsteroidal anti-inflammatory drugs: a nested case-control study. Arthritis Res Ther. 2007;9(3):R52.

59. Hunt RH. Importance of $\mathrm{pH}$ control in the management of GERD. Arch Intern Med. 1999;159(7):649-657.

60. Bianchi PG, Lazzaroni M, Imbesi V, Montrone F, Santagada T. Efficacy of pantoprazole in the prevention of peptic ulcers, induced by non-steroidal anti-inflammatory drugs: a prospective, placebo-controlled, doubleblind, parallel-group study. Dig Liver Dis. 2000;32(3):201-208.

61. Graham DY, Agrawal NM, Campbell DR, et al. Ulcer prevention in long-term users of nonsteroidal anti-inflammatory drugs: results of a double-blind, randomized, multicenter, active- and placebocontrolled study of misoprostol vs lansoprazole. Arch Intern Med. 2002;162(2):169-175.

62. Regula J, Butruk E, Dekkers CP, et al. Prevention of NSAID-associated gastrointestinal lesions: a comparison study pantoprazole versus omeprazole. Am J Gastroenterol. 2006;101(8):1747-1755.

63. Naesdal J, Wilson I. Gastro-duodenal protection in an era of cyclooxygenase-2-selective nonsteroidal anti-inflammatory drugs. Eur $J$ Gastroenterol Hepatol. 2001;13(12):1401-1406.

64. Cullen D, Bardhan KD, Eisner M, et al. Primary gastroduodenal prophylaxis with omeprazole for non-steroidal anti-inflammatory drug users. Aliment Pharmacol Ther. 1998;12(2):135-140.

65. Scheiman JM, Yeomans ND, Talley NJ, et al. Prevention of ulcers by esomeprazole in at-risk patients using non-selective NSAIDs and COX-2 inhibitors. Am J Gastroenterol. 2006;101(4):701-710.

66. Rostom A, Wells G, Tugwell P, Welch V, Dube C, McGowan J. Prevention of NSAID-induced gastroduodenal ulcers. Cochrane Database Syst Rev. 2000;(4):CD002296.

67. Taha AS, Hudson N, Hawkey CJ, et al. Famotidine for the prevention of gastric and duodenal ulcers caused by nonsteroidal antiinflammatory drugs. N Engl J Med. 1996;334(22):1435-1439.

68. Chan FK, Hung LC, Suen BY, et al. Celecoxib versus diclofenac plus omeprazole in high-risk arthritis patients: results of a randomized double-blind trial. Gastroenterology. 2004;127(4):1038-1043.

69. Lai KC, Chu KM, Hui WM, et al. Celecoxib compared with lansoprazole and naproxen to prevent gastrointestinal ulcer complications. Am J Med. 2005;118(11):1271-1278

70. Chan FK, Wong VW, Suen BY, et al. Combination of a cyclo-oxygenase-2 inhibitor and a proton-pump inhibitor for prevention of recurrent ulcer bleeding in patients at very high risk: a double-blind, randomised trial. Lancet. 2007;369(9573):1621-1626.

71. Krol N, Muris JW, Schattenberg G, Grol R, Wensing M. Use of prescribed and non-prescribed medication for dyspepsia. Scand J Prim Health Care. 2004;22(3):163-167.

72. van Soest EM, Siersema PD, Dieleman JP, Sturkenboom MC, Kuipers EJ. Persistence and adherence to proton pump inhibitors in daily clinical practice. Aliment Pharmacol Ther. 2006;24(2):377-385.

73. Gosselin A, Luo R, Lohoues H, et al. The impact of proton pump inhibitor compliance on health-care resource utilization and costs in patients with gastroesophageal reflux disease. Value Health. 2009;12(1):34-39. 
74. El-Serag HB, Fitzgerald S, Richardson P. The extent and determinants of prescribing and adherence with acid-reducing medications: a national claims database study. Am J Gastroenterol. 2009;104(9):2161-2167.

75. Cleemput I, Kesteloot K, DeGeest S. A review of the literature on the economics of noncompliance. Room for methodological improvement. Health Policy. 2002;59(1):65-94.

76. Hughes DA, Bagust A, Haycox A, Walley T. The impact of noncompliance on the cost-effectiveness of pharmaceuticals: a review of the literature. Health Econ. 2001;10(7):601-615.

77. Brown TJ, Hooper L, Elliott RA, et al. A comparison of the costeffectiveness of five strategies for the prevention of non-steroidal anti-inflammatory drug-induced gastrointestinal toxicity: a systematic review with economic modelling. Health Technol Assess. 2006;10(38): iii-iv, xi-xiii, 1-183.
78. Cuzick J, Otto F, Baron JA, et al. Aspirin and non-steroidal anti-inflammatory drugs for cancer prevention: an international consensus statement. Lancet Oncol. 2009;10(5):501-507.

79. Bolten WW, Lang B, Wagner AV, Krobot KJ. [Consequences and costs of NSAID-induced gastropathy in Germany]. Akt Rheumatol. 1999;24: 127-134.

80. Bolten WW. Spektrum Nichtsteroidale Antirheumatika (NSAR). In: Petersen KU, editor. Arzneimitteltherapie heute. 2nd ed. Aesopus; 2004:25-34.

\section{Publish your work in this journal}

Orthopedic Research and Reviews is an international, peer-reviewed, open access journal focusing on the patho-physiology of the musculoskeletal system, trauma, surgery and other corrective interventions to restore mobility and function. Advances in new technologies, materials, techniques and pharmacological agents are particularly welcome. The journal welcomes original research, clinical studies, reviews \& evaluations, expert opinion and commentary, case reports and extended reports. The manuscript management system is completely online and includes a very quick and fair peer-review system, which is all easy to use. Visit http://www.dovepress. com/testimonials.php to read real quotes from published authors.

Submit your manuscript here: http://www.dovepress.com/orthopedic-research-and-reviews-journal 